\begin{tabular}{|c|c|c|}
\hline \multirow{2}{*}{ BENTHAM OPEN } & $\begin{array}{c}\text { The Open Construction and Building } \\
\text { Technology Journal }\end{array}$ & $\begin{array}{l}\text { The Open } \\
\text { Constraction \& Building } \\
\text { Technology lournal }\end{array}$ \\
\hline & $\begin{array}{l}\text { Content list available at: www.benthamopen.com/ТОВСТJ/ } \\
\text { DOI: } 10.2174 / 1874836801610010001\end{array}$ & Farestio \\
\hline
\end{tabular}

\title{
Experimental Studies on Cohesion of Carbon Fibre Reinforced Polymer for Reinforcement of Bridge Deck Slabs
}

\author{
Tian Shuai $^{1,2, *}$, Yu Tianlai ${ }^{1}$, Zhao Yunpeng $^{1,3}$, Guo Weimin $^{3}$ and Li Haisheng ${ }^{1}$ \\ ${ }^{1}$ Civil Engineering College, Northeast Forestry University, Harbin, 150040, China \\ ${ }^{2}$ School of Civil Engineering, Liaoning University of Science and Technology, Anshan 114051, China \\ ${ }^{3}$ Traffic Planning and Design Institute of Liaoning Province, Shenyang, 110166, China
}

\begin{abstract}
Bridge deck slabs reinforced by carbon fibre reinforced polymer (CFRP) are subjected to a number of problems related to cohesion, such as slippage, disengaging, and debonding. In order to address such problems, we conducted indoor shear, stretching, and debonding tests, analysed the change rule of cohesion in these three different environments, and determined the optimum construction technique for improving the cohesion of CFRP. We found that to obtain acceptable shear strength, manufactured sand should be spread on the surface of the impregnating resin adhesive. Soaking, freeze thawing, and wheel grinding processes affected the tensile strength of the interface, which was related linearly to the shear strength of the interface. Following wheel grinding on an asphalt surface at high temperatures, the test value for the bearing-debonding capacity on a test slab was unchanged, and the effectiveness of the CFRP was still apparent. The influence of high-temperature wheel grinding can be ignored. This study can serve as a reference for the design of reinforced bridge deck slabs.
\end{abstract}

Keywords: Bridge deck pavement, Bridge deck slabs, Carbon fibre reinforced polymer, Cohesion, Debonding, Reinforcement.

\section{INTRODUCTION}

In recent years, the appearance of vertical cracks has been observed in many bridges worldwide, which has affected the normal operation of a number of bridges. In particular, the effects of extreme weather have resulted in the appearance of vertical cracks in the bridge deck slabs of the Bangabandhu Bridge in Bangladesh [1]. The number, length, and width of these cracks appear to increase over time, with the Tonghui River Bridge, Jiujiang Yangtze River Bridge, Li River Second Bridge, and Guanghua Bridge in China all suffering from worsening vertical cracks in their bridge deck slabs. In recent years, several vertical cracks have also appeared on the Baishizhou Yangtze River Approach Bridge (Fig. 1) and the Liming High Level Bridge in Fujian Province (Fig. 2). The bridge deck slabs of these bridges therefore require urgent reinforcement and reparation.

Currently, the use of carbon fibre reinforced polymer (CFRP) is preferred for the reinforcement of bridge deck slabs as it is a fast, low cost method, which imparts minimal damage to the beams. However, a number of issues caused by different kinds of cohesion must be taken into account when reinforcing deck slabs with CFRP. These issues are summarised in Fig. (3). Firstly, slippage between the deck pavement and CFRP sheets can occur, caused by the braking force of vehicles (Fig. 3a). In addition, disengagement between the deck pavement and the CFRP sheets can take place due to vibration from the vehicles (Fig. 3a). Finally, debonding between the deck concrete and the CFRP sheets can occur due to wheel grinding at high temperatures on the asphalt surface during construction. It is therefore necessary to investigate these issues and evaluate the cohesion properties of CFRP.

\footnotetext{
* Address correspondence to this author at the School of Civil Engineering, Liaoning University of Science and Technology, Anshan 114051, China; Tel: +86-13942206793; Fax: +86-04125599006; E-mail: tian_shuai129@126.com
} 


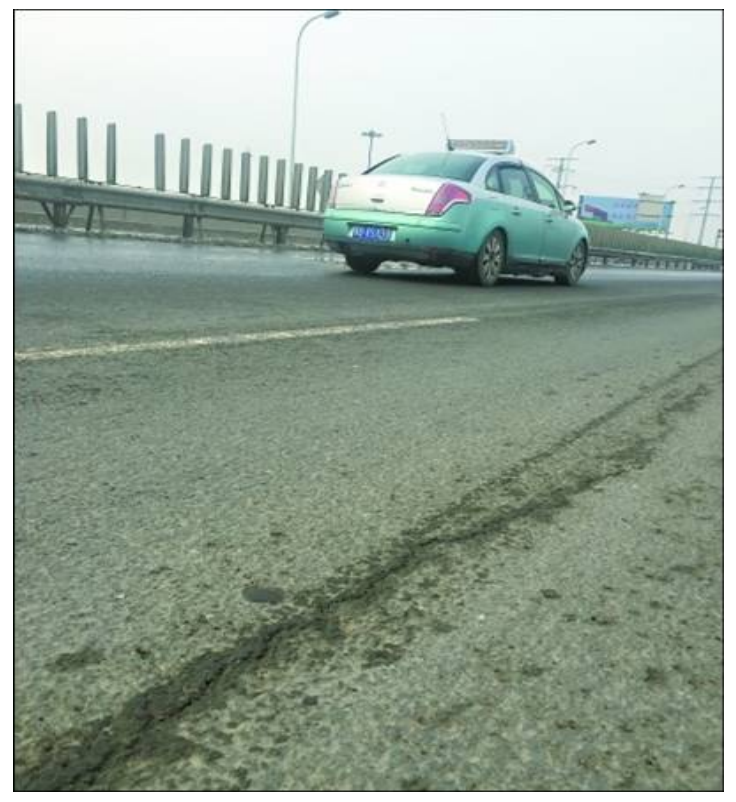

Fig. (1). Vertical cracks on the Baishizhou Yangtze River Approach-Bridge

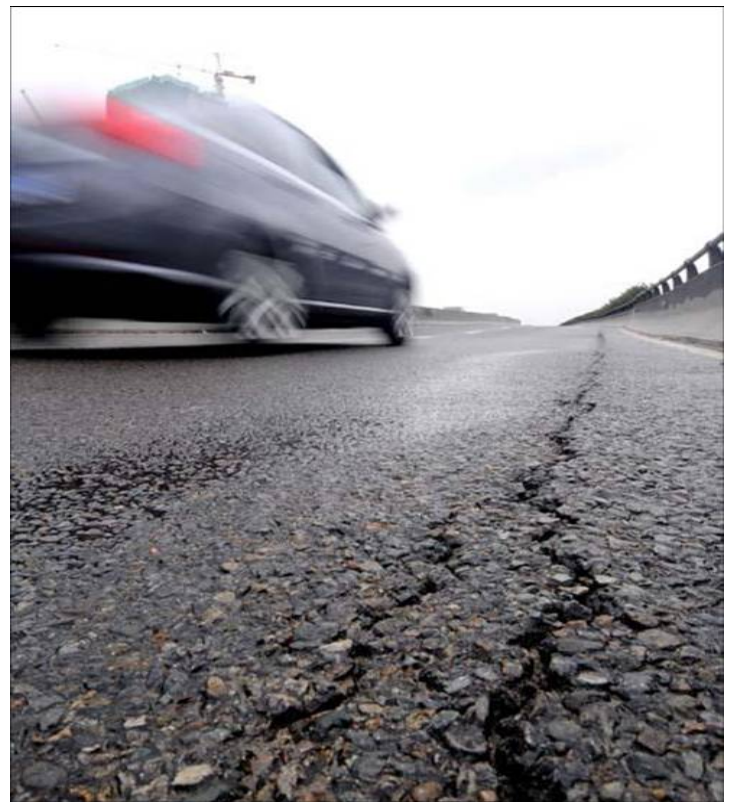

Fig. (2). Vertical cracks on the liming high level bridge in Fujian province.

A number of experimental and theoretical investigations have been conducted on concrete slabs reinforced by CFRP in recent years. In particular, studies have focused on bearing capacities [2, 3], mechanical calculations [4, 5], anchorage methods [6], and durability properties [7], among others [8,9]. However, few studies have investigated the use of CFRP bonded on the top surface of bridge deck slabs.

We herein report the use of sheared specimens, stretched specimens, and steel concrete in indoor simulation experiments for the measurement of shear strength and stretching strength of the interface between the bridge deck pavement and bridge deck slabs reinforced with CFRP. In addition, we plan to analyse the rules of influence of surrounding environments on bearing, shear, and stretching, and determine the optimum construction technique for improving these capacities of the interface. We also aim to conduct high-temperature indoor simulation destruction experiments on steel concrete slabs reinforced with CFRP, and investigate the related theoretical analysis, debonding properties of CFRP, and the effect of high-temperature wheel grinding on CFRP. Finally, we will discuss measures to control debonding diseases of CFRP. 


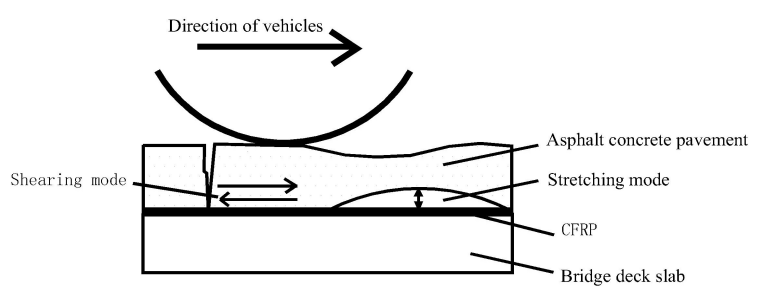

(a) Slippage and disengagement damage.

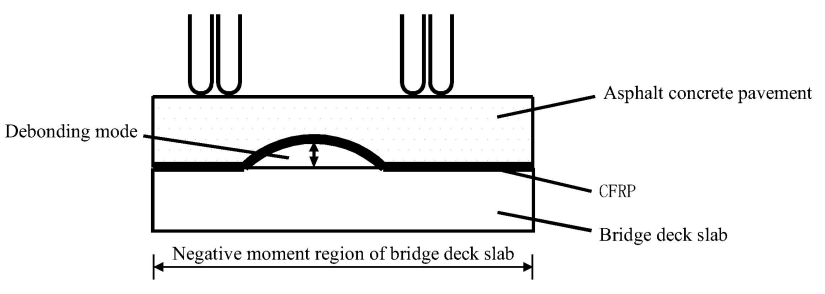

(b) Debonding damage.

Fig. (3). Damage of CFRP on bridge deck slabs.

\section{MATERIALS AND METHODS}

\subsection{Indoor Shear Tests}

Fig. (4) shows the configuration of the shear test, which consists of a self-made shearing-fixture, force-measuring sensor, and data logger. To simulate loads from vehicles, a vertical load was introduced to simulate braking force, a horizontal load was introduced using a spring to simulate force from vehicle wheels, and subsequently, the largest shear force was measured.

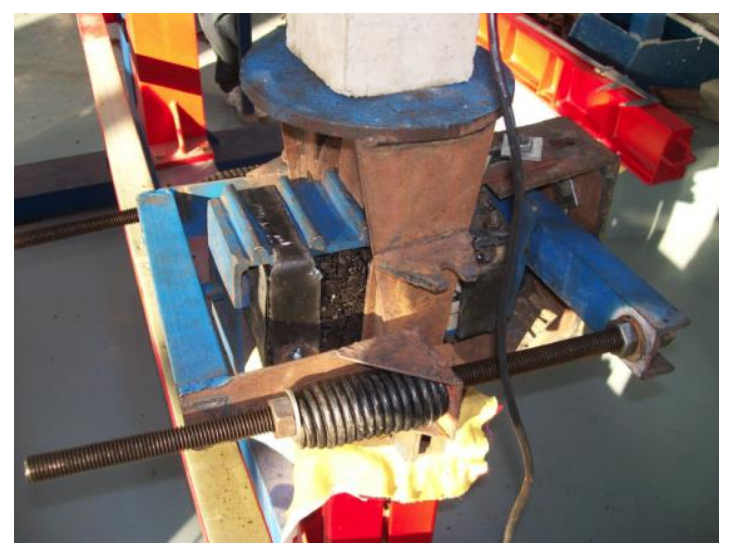

(a) Experimental shear test apparatus.

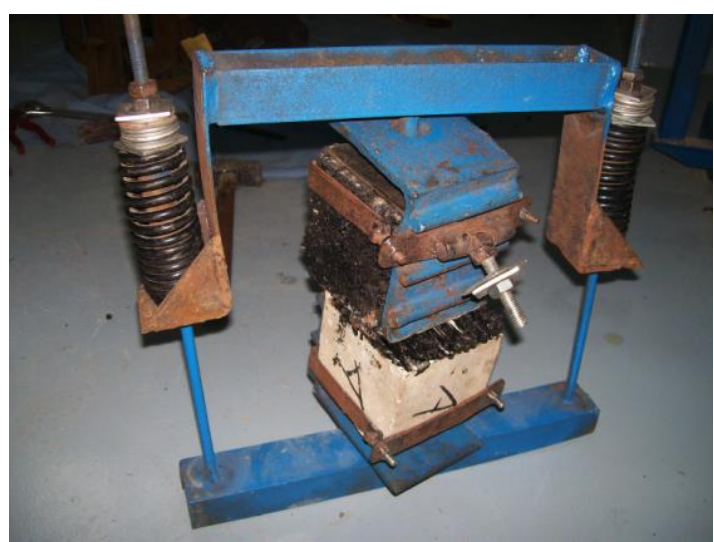

(b) Break-in shear tests.

Fig. (4). Shear test set-up.

Fig. (5) demonstrates the size of the specimens. The bottom section is composed of $\mathrm{C} 30$ cement concrete, the middle section is a waterproof bonding interface (5\% SBS modified asphalt), and the top section is AC-16I modified asphalt concrete.

In these experiments, cement concrete was used to simulate the bridge slab, whereas asphalt concrete was used to simulate the bridge pavement. The designed test method involved the preparation of three cement concrete specimens with different surface properties according to the data shown in Table $\mathbf{1 .}$

Table 1. Preparation of cement concrete specimens.

\begin{tabular}{|c|c|c|}
\hline Number & Condition & Method of preparation \\
\hline 1 & Original interface $^{\mathrm{a}}$ & Stoving, clearing out laitance and ash. \\
\hline 2 & CFRP-interface $^{\mathrm{b}}$ & $\begin{array}{c}\text { CFRP sheet stuck to original interface with base gel and main gel in a 1:0.35 ratio, followed by solidifying under } \\
\text { standard conditions }\end{array}$ \\
\hline 3 & CFRP+sand interface & $\begin{array}{c}\text { After sticking the CFRP sheet to the original interface, sand was spread on the main gel before solidification, } \\
\text { compacted, loose sand removed with an air compressor, and finally, solidification was carried out according to } \\
\text { standard conditions. }\end{array}$ \\
\hline
\end{tabular}

${ }^{a}$ Specimen prepared as for a bridge slab. ${ }^{b}$ A CFRP sheet was stuck to the original interface. ${ }^{c}$ AECR resin adhesive was painted onto the CFRP sheet and manufactured sand was spread on the surface (diameter $=2.36-4.75 \mathrm{~mm}$ ). 


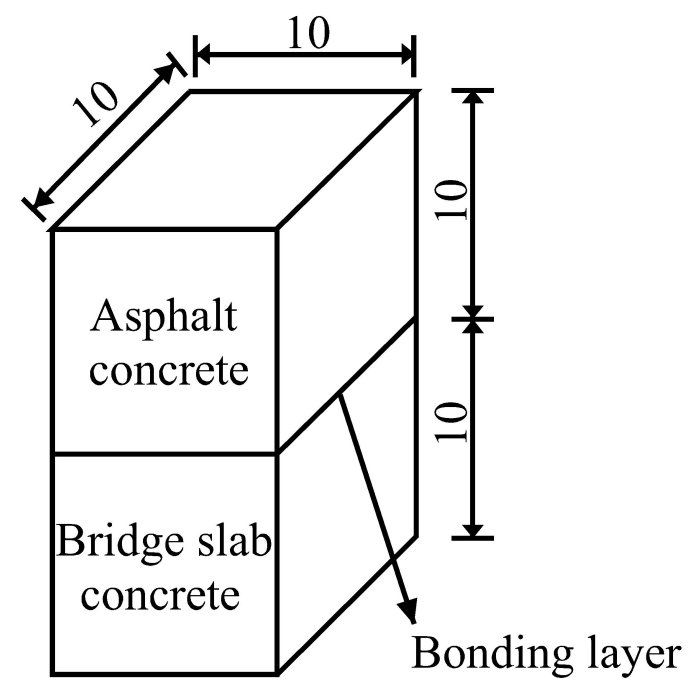

Fig. (5). Size of shear specimen (measurements in centimetres).

According to China's concrete code, standard C30 concrete's compressive strength and tensile strength are 20.1 and 2.01 MPa, respectively, and its elasticity modulus is $3.0 \times 10^{4} \mathrm{MPa}$. The CFRP materials used were CFRP sheets made in Taiwan (thickness $=1.4 \mathrm{~mm}$ ). According to the CFRP mechanical performance specifications, a tensile strength of $2300 \mathrm{MPa}$ and a tensile elasticity modulus of $235 \mathrm{GPa}$ were recorded, along with a compressive strength of $>70 \mathrm{MPa}$. A special CFRP bonding glue (Beijing) was used. According to the mechanical performance specifications of the bonding glue, a tensile strength of $25 \mathrm{MPa}$, a tensile elasticity modulus of $2500 \mathrm{MPa}$, and a compressive strength of $>70 \mathrm{MPa}$ were recorded.

The shear strength of the interface, $\tau$, can be calculated according to Equation (1):

$$
\tau=F / S
$$

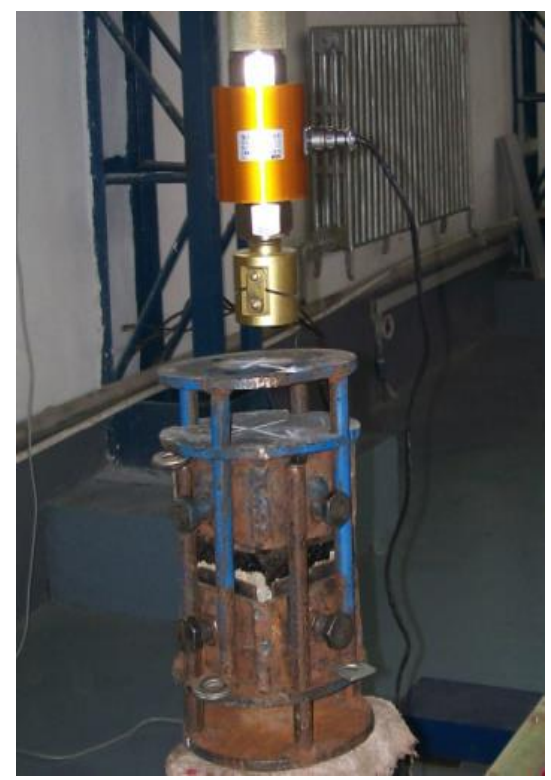

(a) Experimental apparatus.

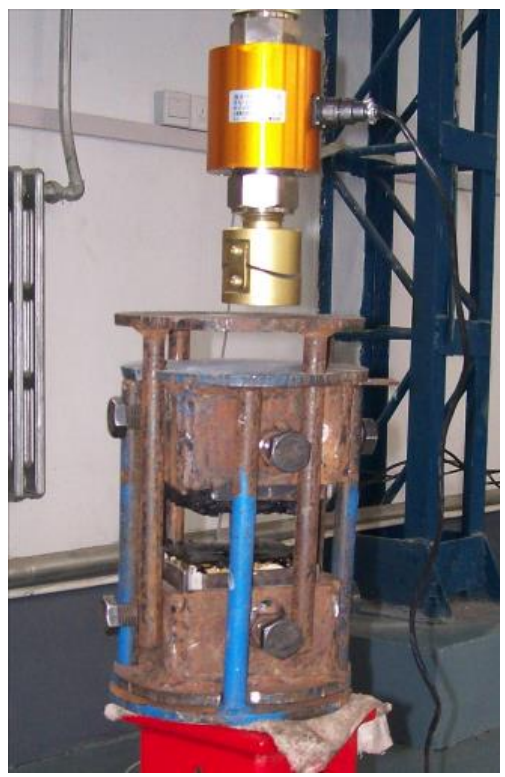

(b) Break-in tensile strength experiment.

Fig. (6). Tensile strength experimental set-up.

where $F$ is the maximum value of the shear force and $S$ is the interface shear area. The wheel load for the test was set at $0.7 \mathrm{MPa}$. 


\subsection{Indoor Tensile Strength Experiments}

Specimen preparation was as described for the shear tests. Sand was spread on the sample over $8 \mathrm{~h}$, and $1.3 \mathrm{~kg} / \mathrm{m}^{2}$ modified asphalt was used. The specimens were carried using a self-made clamp, as shown in Fig. (6). Tensile strength experiments were then conducted and the tensile strength was calculated according to Equation (2):

$$
f_{v}=\frac{N}{S}
$$

where $f_{v}$ is the tensile strength, $N$ is the maximum tension value, and $S$ is the tensile area of the interface.

\subsection{Indoor Debonding Experiments}

\subsubsection{Simulation of Specimen Construction}

Before asphalt concrete was spread, the specimens were buried in an appropriate location, and the CFRP reinforced specimens were subjected to wheel grinding at high temperatures, as shown in Fig. (7). When the temperature had dropped back to ambient temperature, the specimens were removed. These experiments involved subjecting two different specimens to wheel grinding at high temperatures, simulating the temperatures used in construction (130$\left.150{ }^{\circ} \mathrm{C}\right)$. The debonding experiments described here are therefore of representative value.

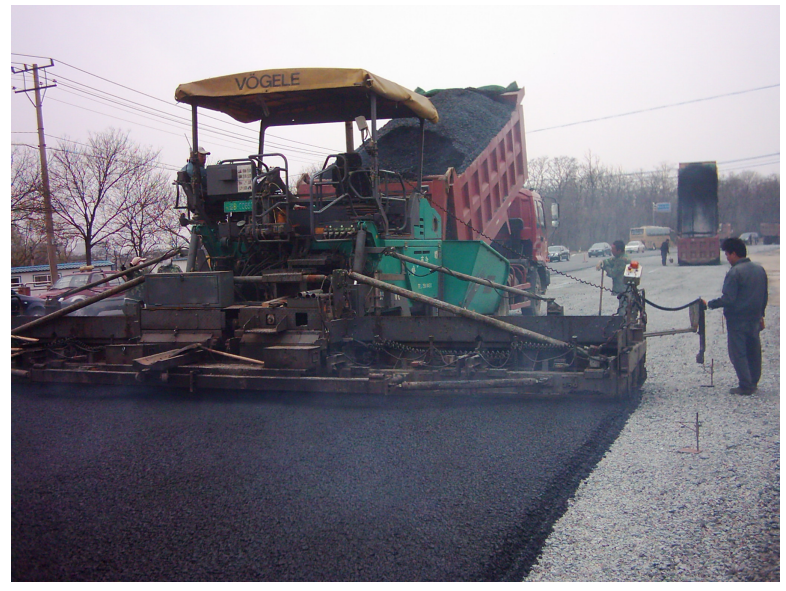

(a) Spreading process.

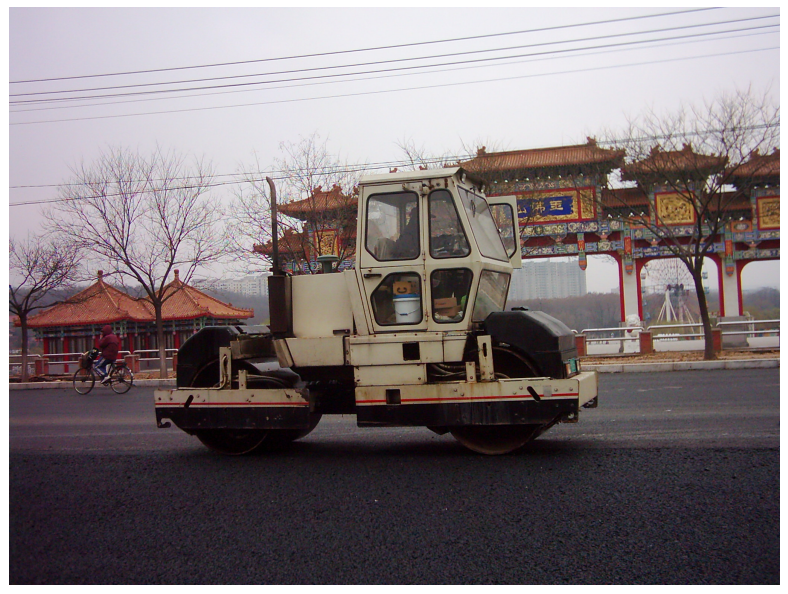

(b) Wheel grinding process.

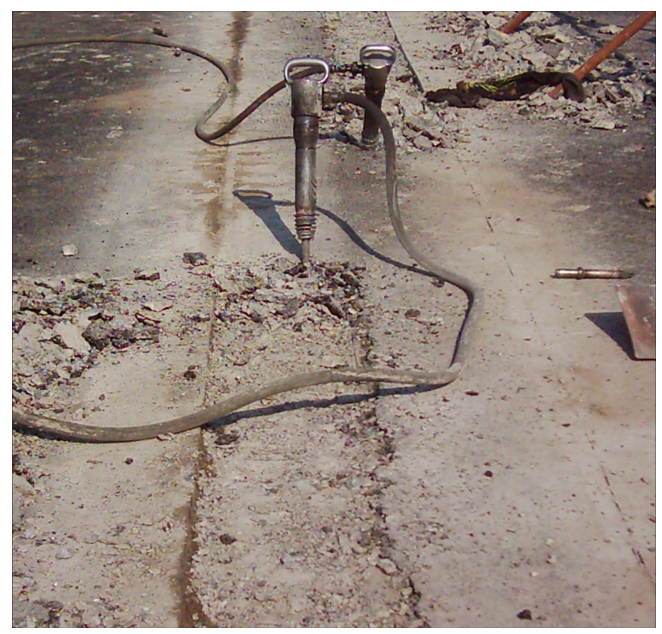

(c) Removal of specimens.

Fig. (7). Construction site. 


\subsubsection{Designed Reinforcement and Loading Method}

According to the vehicle loading effect, the CFRP sheet should be horizontally bonded onto bridge slabs in negative bending regions. Only in this way can vertical cracks be restricted, and the destruction of bridge pavements delayed. According to the standard T-beam size, the specimen section measures $1.6 \times 0.4 \times 0.1 \mathrm{~m}^{3}$ (length $\times$ width $\times$ height). The purpose of this experiment is to simulate CFRP-reinforcement onto T-beams in negative bending regions, and the results are applicable for the reinforcement of box-beam bridge slabs.

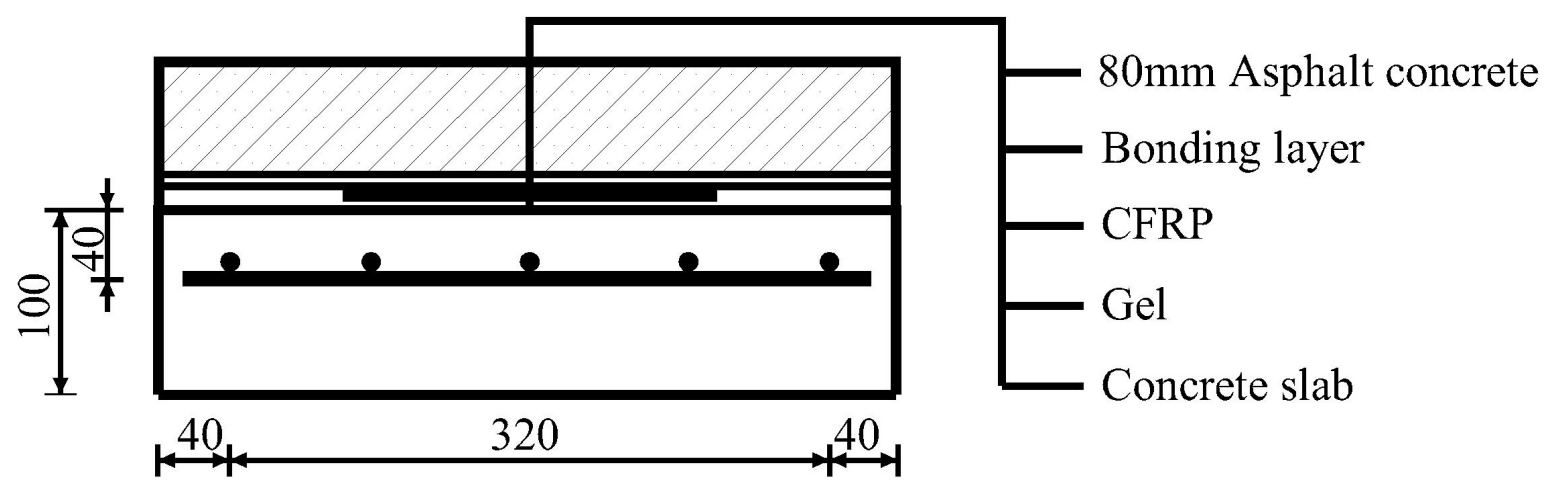

Fig. (8). Cross-section of the CFRP-reinforcement (measurements are in millimetres).

Two CFRP strips (thickness $=1.4 \mathrm{~mm}$, width $=100 \mathrm{~mm}$ ) were used in the reinforcement experiments along with $\mathrm{C} 30$ concrete. With pouring onto the test slab, nine cubic specimens $(150 \mathrm{~mm} \times 150 \mathrm{~mm} \times 150 \mathrm{~mm})$ were prepared and conserved for $28 \mathrm{~d}$. The average measured compressive strength of the specimens was $36.8 \mathrm{MPa}$, which was $6.8 \mathrm{MPa}$ higher than that of $\mathrm{C} 30$ concrete. Hence, the test slab meets the test requirement. HRB335 twisted steel with a diameter of $10 \mathrm{~mm}$ was used in the tensile regions. As shown in Fig. (8), the reinforcement simulation involved the inclusion of a horizontal CFRP sheet.

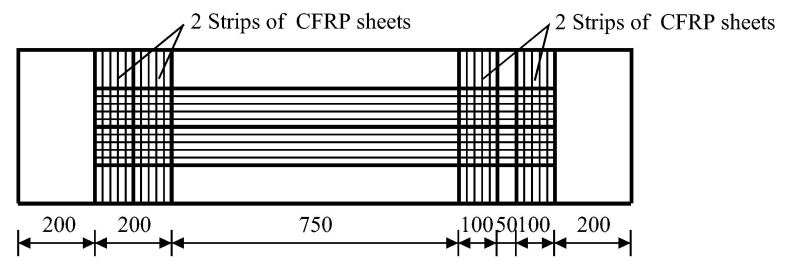

(a) JM-1.

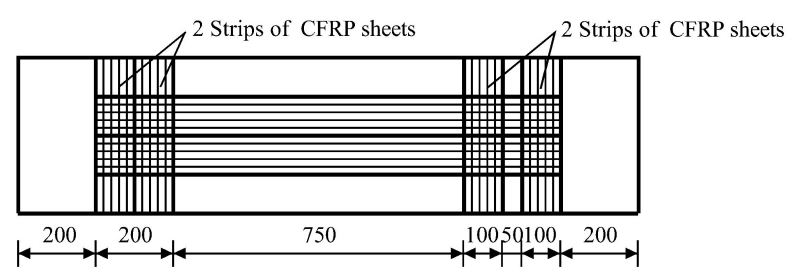

(c) TM-1.

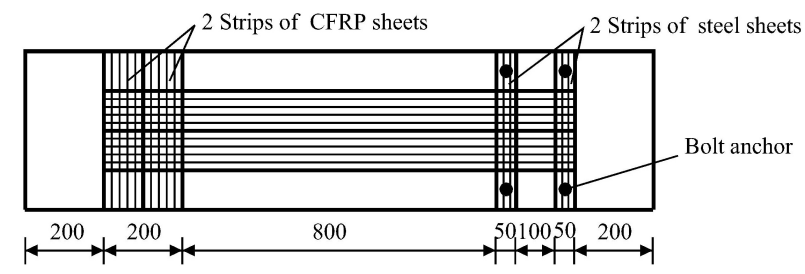

(b) JM-2.

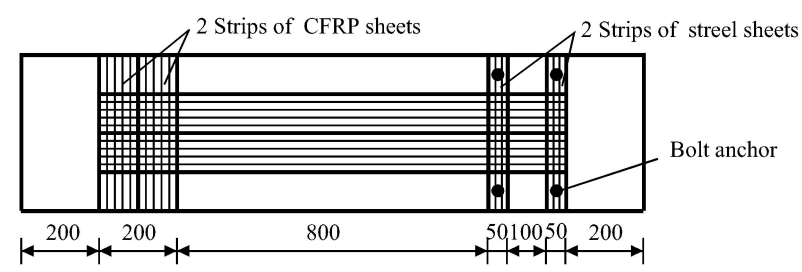

(d) TM-2.

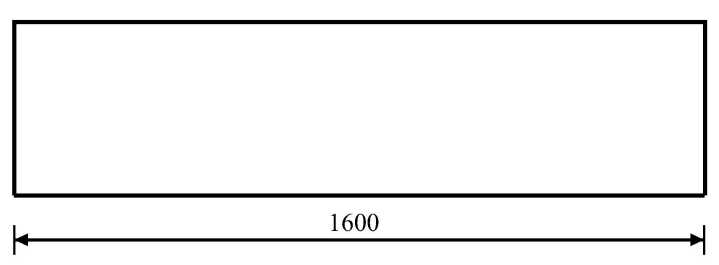

(e) JM-0.

Fig. (9). Reinforcement design and anchor method (measurements are in millimetres). 
As shown in Fig. (9), the reinforcement design and anchor method are as follows: 1) Anchoring with a CFRP sheet on both ends of the specimen slab (JM-1);2) Anchoring with a CFRP sheet on one end and bolt on the other end (JM-2); 3) Anchoring with a CFRP sheet on both ends of the specimen slab, followed by grinding at high temperatures (TM-1); 4) Anchoring with a CFRP sheet on one end and bolt on the other end, followed by grinding at high temperatures (TM-2); and 5) A concrete slab without reinforcement (JM-0).

Single point loading on the midspan of a simply supported slab was performed in this experiment, as shown in Fig. (10). During loading, the side of the slab bonded with CFRP was placed facing downward. The distance between the supports was $1400 \mathrm{~mm}$. In addition, a piece of I-shaped steel (width $=160 \mathrm{~mm}$ ) and a rubber blanket (thickness $=5$ $\mathrm{mm}$ ) were placed under the loading point. Before loading, a preload was first conducted, followed by formal loading. The values were taken when the value became stable.

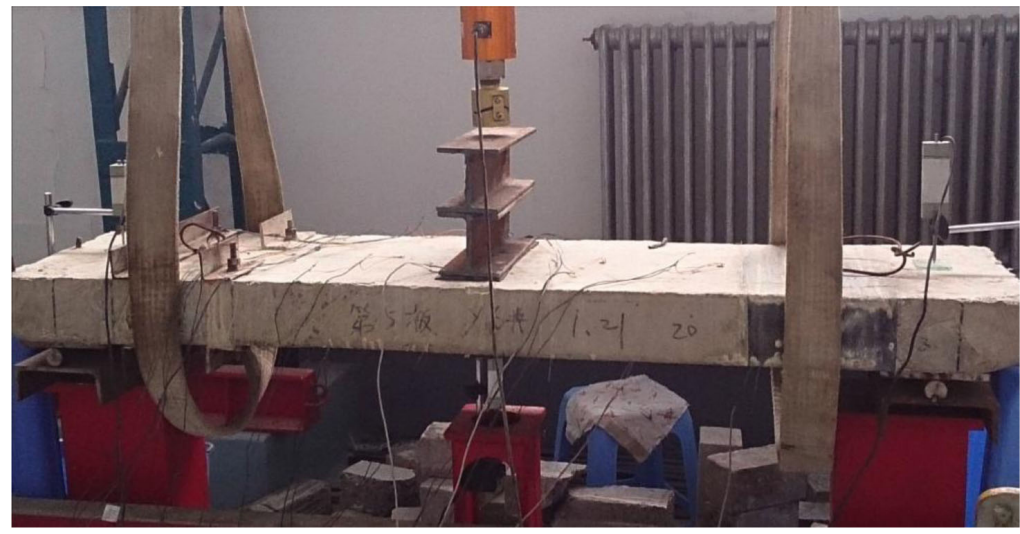

Fig. (10). Loading installation.

\subsubsection{Theoretical Analysis of the Bearing-Debonding Capacity}

It was expected that bending members reinforced by CFRP sheets may suffer from debonding destruction caused by bending cracks in the middle segment. The destruction mechanism involves formation of a bending crack in the concrete, resulting in a release of concrete tensile stress in the cracking interface.

This stress was transmitted to the CFRP sheets, leading to an increase in stress in the interface between the CFRP sheets and the concrete close to the cracks. With an increase in load, the tensile stress of the CFRP sheets and the stress in the interface between the CFRP sheets and the concrete close to the cracks also increased.

When stress at the interface reached its maximum value, debonding occurred in the cracks, eventually running through the whole specimen. Only a thin layer of concrete remained on the debonded CFRP sheet following this process. Vertical steel surrenders were employed, followed by CFRP sheet debonding from the middle segment to the end of the specimen.

\section{RESULTS AND DISCUSSION}

\subsection{Indoor Shear Tests}

\subsubsection{Influence of Temperature on Interface Shear Strength}

The influence of temperature on shear strength of the interface was measured at $-40{ }^{\circ} \mathrm{C}, 25{ }^{\circ} \mathrm{C}, 40^{\circ} \mathrm{C}$, and $60{ }^{\circ} \mathrm{C}$. Sand $\left(3.0 \mathrm{~kg} / \mathrm{m}^{2}\right)$ was then spread on the main gel over $6 \mathrm{~h}$. Modified asphalt $\left(1.0 \mathrm{~kg} / \mathrm{m}^{2}\right)$ was used in each of the three specimens. The results of these tests are shown in Fig. (11).

As can be seen in Fig. (11), at low temperatures, the shear strength on the CFRP-interface performs better than the original interface, whereas at ambient and high temperatures, the shear strength of the CFRP-interface is comparable to that of the original interface. Finally, it was found that the shear strength of the CFRP + sand interface was higher than that of the other interfaces except at the highest temperatures. 


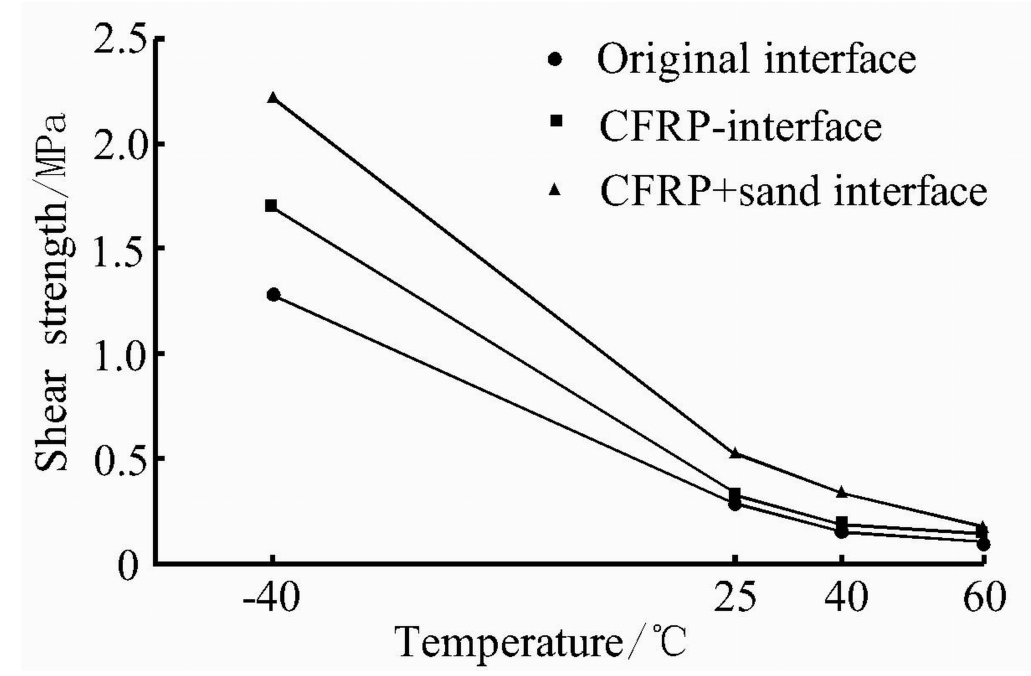

Fig. (11). Plot of shear strength against temperature for the three interfaces.

\subsubsection{Determination of Optimal Modified Asphalt Quantity}

The influence of modified asphalt quantity on the shear strength of the CFRP + sand interface was then investigated at $-40{ }^{\circ} \mathrm{C}, 25^{\circ} \mathrm{C}, 40^{\circ} \mathrm{C}$, and $60{ }^{\circ} \mathrm{C}$, and the results given in Fig. (12). The quantities of modified asphalt used were $0.8 \mathrm{~kg} / \mathrm{m}^{2}, 1.0 \mathrm{~kg} / \mathrm{m}^{2}, 1.3 \mathrm{~kg} / \mathrm{m}^{2}, 1.5 \mathrm{~kg} / \mathrm{m}^{2}$. All other variables were kept constant.

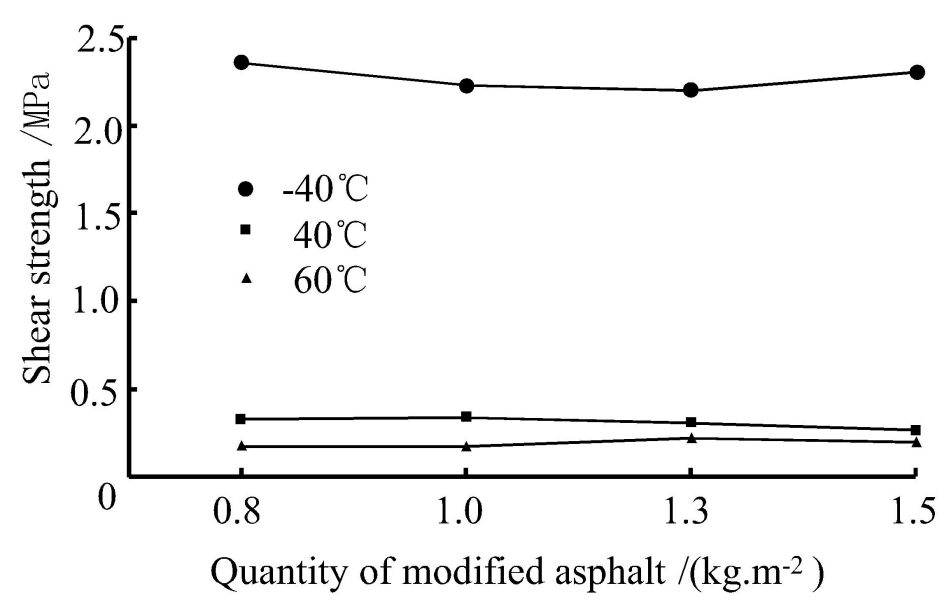

Fig. (12). Shear strength of interfaces with varying modified asphalt quantities.

As shown in Fig. (12), the bonding stress of the interface decreases with an increase in temperature, where equal amounts of modified asphalt were used. In addition, it was observed that varying the amount of modified asphalt had little influence on the shear strength of the interface at the same temperature. As recorded in the construction technical specifications, the amount of modified asphalt should be no lower than $1.0 \mathrm{Kg} / \mathrm{m}^{2}$. Using the specifications and data from the tests at high temperature, we determined the amount of modified asphalt to be $1.3 \mathrm{Kg} / \mathrm{m}^{2}$.

\subsubsection{Determination of Optimal Sand Spreading Time}

As the standard temperature used for bridge pavement construction is $15^{\circ} \mathrm{C}$, we selected this temperature for our tests. All other variables were kept constant. Sand was spread on the gel over 4 h, 6 h, 8 h, and 10 h, and the optimum spreading time was determined as shown in Fig. (13). 


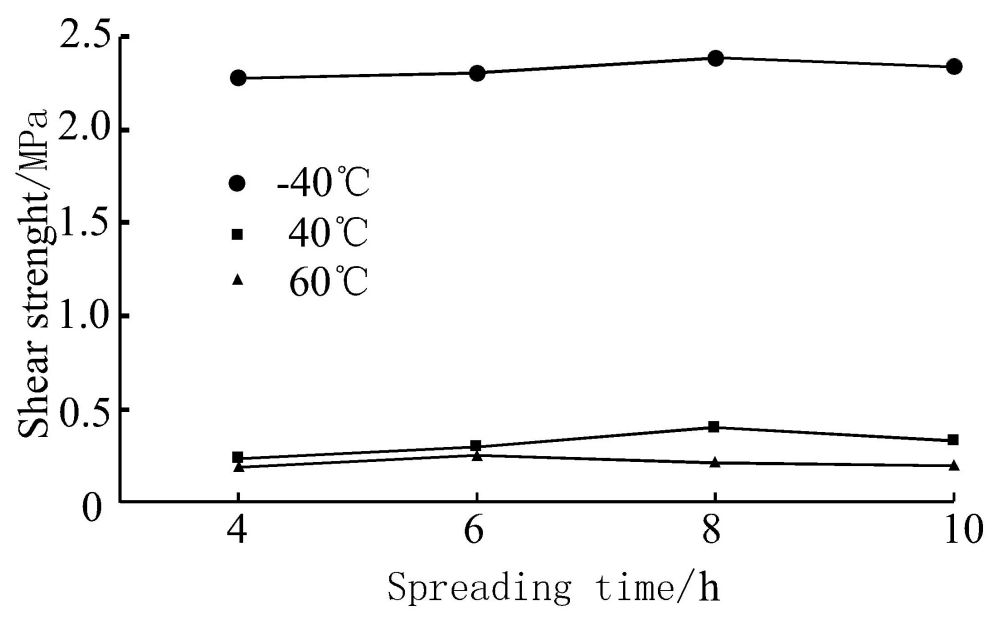

Fig. (13). Shear strength of interfaces with different spreading times.

From Fig. (13) it can be seen that at a temperature of $-40{ }^{\circ} \mathrm{C}$, sand spreading over $8 \mathrm{~h}$ results in the highest shear, with $8 \mathrm{~h}$ also being the optimal spreading time at $40{ }^{\circ} \mathrm{C}$. However, at $60{ }^{\circ} \mathrm{C}$, the shear strength obtained from sand spreading over $8 \mathrm{~h}$ was slightly lower than spreading over $6 \mathrm{~h}$. We could therefore conclude that $8 \mathrm{~h}$ was the optimal spreading time for this process at our desired temperatures.

\subsection{Indoor Tensile Strength Experiments}

\subsubsection{Influence of Temperature on the Tensile Strength of the Interface}

The influence of temperature on tensile strength of the interfaces at $0{ }^{\circ} \mathrm{C}, 20^{\circ} \mathrm{C}$, and $60{ }^{\circ} \mathrm{C}$ was investigated, and the results are shown in Fig. (14).

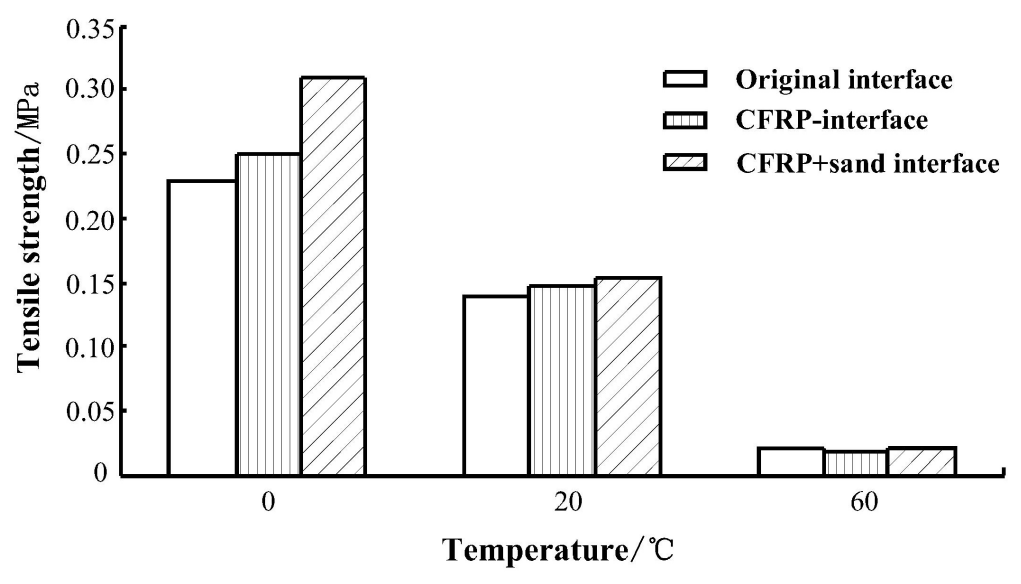

Fig. (14). Variation in tensile strength with temperature.

From Fig. (14), it can be seen that the variation in cohesion of the three interfaces is particularly large at $0{ }^{\circ} \mathrm{C}$, but less apparent at $20^{\circ} \mathrm{C}$ and negligible at $60^{\circ} \mathrm{C}$. This result allows us to conclude that the tensile cohesion of AECR resin and modified asphalt drop significantly with an increase in temperature.

\subsubsection{Influence of Soaking, Freeze Thawing, and Wheel Grinding on Interface Tensile Strength}

The tensile strengths of the interfaces were then measured following soaking, freeze thawing, and wheel grinding. The specimens were split into two groups. Group 1 was subjected to tensile strength experiments directly, while Group 2 was exposed to standard soaking, freeze thawing, and wheel grinding before testing. A test temperature of $0{ }^{\circ} \mathrm{C}$ was used throughout. The results from these experiments can be seen in Fig. (15). 


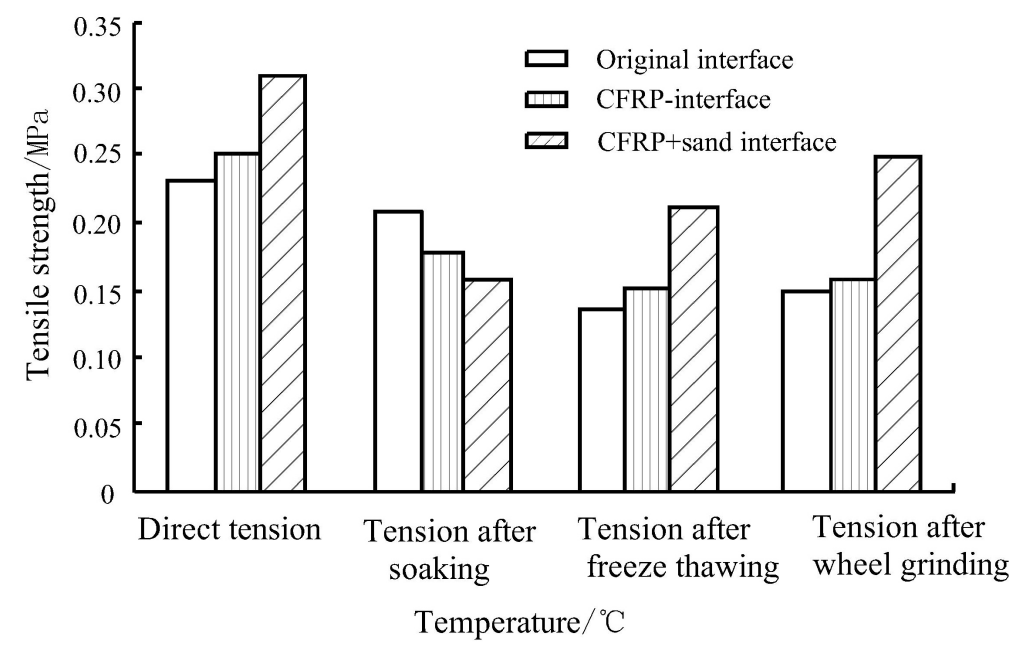

Fig. (15). Variation in tensile strength upon soaking, freeze thawing, and wheel grinding at $0{ }^{\circ} \mathrm{C}$.

Fig. (15) shows that soaking, freeze thawing, and wheel grinding have an obvious detrimental effect on tensile strength. It was found that soaking has the largest influence on the tensile strength of the CFRP+sand interface, while all three treatments had comparable effects on the CFRP interface. Overall, it was found that the CFRP+sand interface resulted in an optimal tensile strength compared to the other interfaces studied.

\subsubsection{Relationship between Tensile Strength and Shear Strength}

Specimens were prepared using $1.3 \mathrm{~kg} / \mathrm{m}^{2}$ modified asphalt, and a sand spreading time of $8 \mathrm{~h}$. Test temperatures of $0{ }^{\circ} \mathrm{C}, 20^{\circ} \mathrm{C}$, and $60{ }^{\circ} \mathrm{C}$ were used to conduct shear tests on the three interfaces and to analyse the relationship between tensile strength and shear strength. The results for these experiments are shown in Fig. (16).

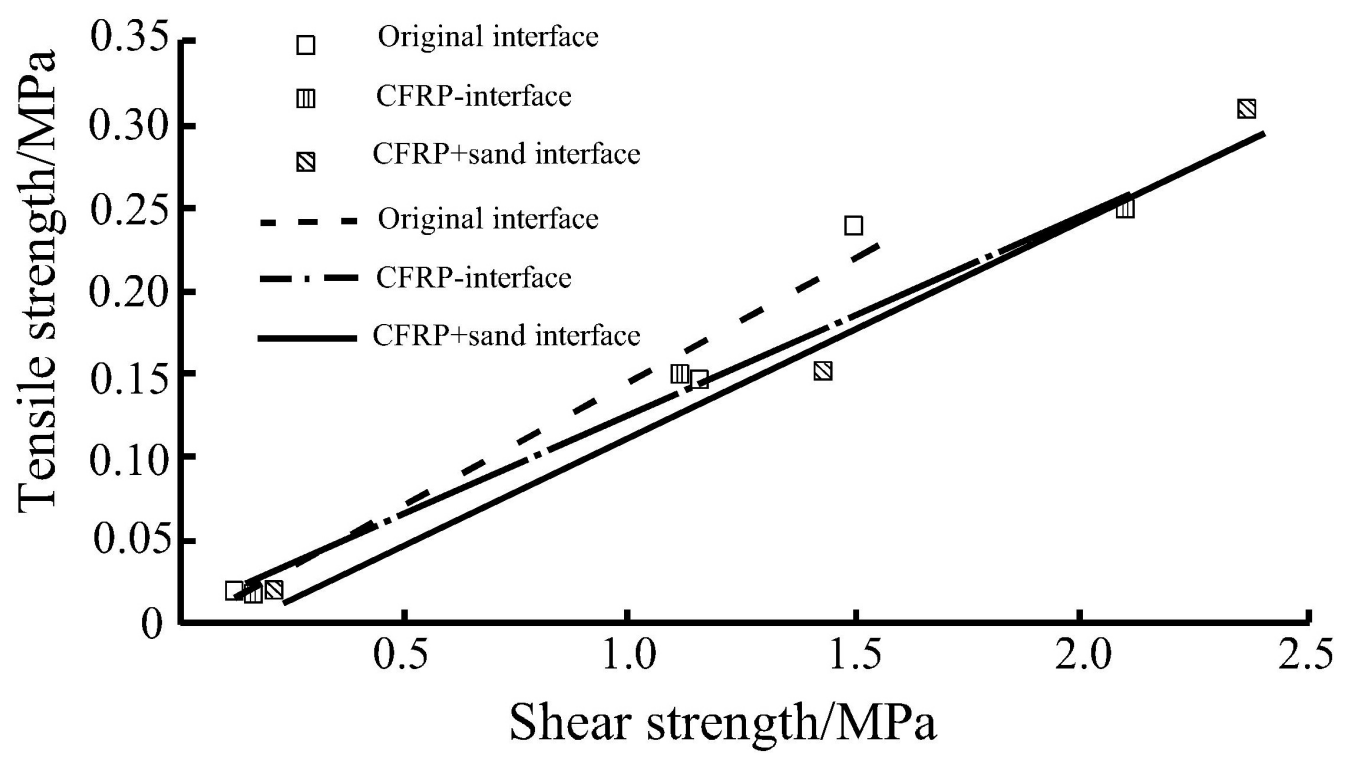

Fig. (16). Relationship between tensile strength and shear strength.

The results were analysed according to the linear regression method (Equations 3-5), and the related coefficients were calculated to be $0.976,0.997,0.993$.

Original interface: $f_{v}=0.144 \tau-0.00060$;

CFRP-interface: $f_{v}=0.119 \tau+0.0004$; 
CFRP+sand interface: $f_{v}=0.133 \tau-0.016$;

Results from these experiments show that all three interfaces exhibit good linear relationships, confirming that the shear and tensile properties are related to one another. At the same temperature, the shear strength was larger than tensile strength in the same interface, with the former being 6-9 times larger than the latter. Furthermore, with an increase in temperature, the decreasing range of shear strength was larger than that of tensile strength. This was most obvious in the CFRP+sand interface, but less obvious in the CFRP interface and the original interface. Fig. (17) shows the interface comparisons following the shear tests and tensile experiments. It can be seen that the shear specimens displayed greater destruction, whereas the tensile specimens remained largely intact.

\subsection{Indoor Debonding Experiments}

\subsubsection{Debonding Stress Caused by Bending Cracks}

Chen An Teng [10] reported the combination of breakage mechanics with experimental results, and proposed a calculated value of the debonding stress of CFRP $\sigma_{d b i c}$ as shown in Equation (6):

$$
\sigma_{d b i c}=0.4 \beta_{p} \beta_{L} \sqrt{\frac{E_{C F R P} \sqrt{f_{c}^{\prime}}}{t_{C F R P}}}
$$

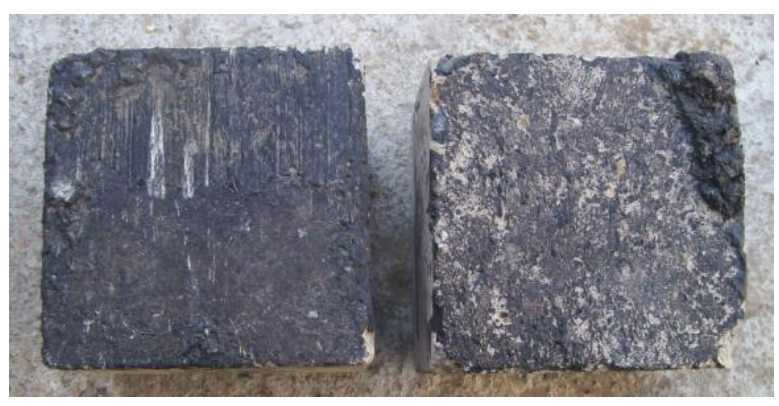

(a) Original interface.

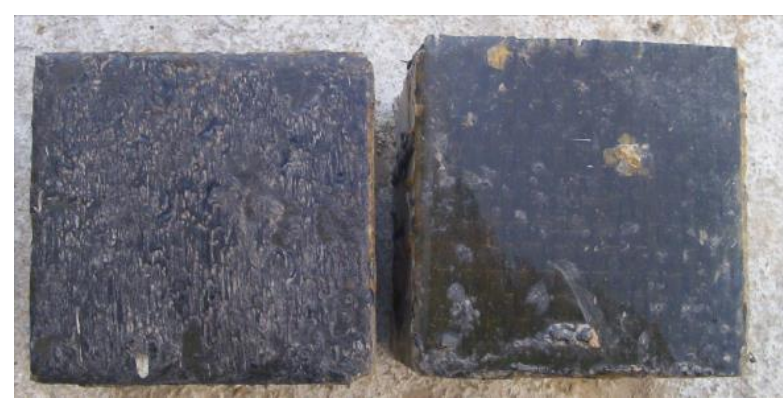

(b) CFRP interface.

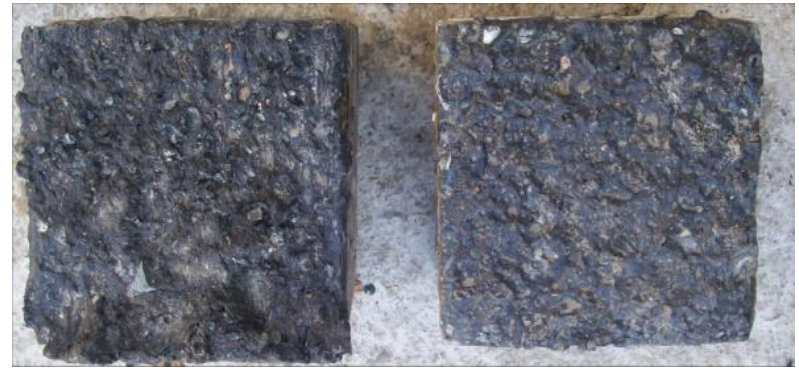

(c) CFRP+sand interface.

Fig. (17). Interface comparisons in shear tests and tensile experiments $(\mathrm{left}=\mathrm{shear}$, right $=$ tension $)$. 
where the width ratio coefficient $\beta_{p}$ can be calculated according to Equation (7):

$$
\beta_{p}=\sqrt{\frac{2-\frac{b_{p}}{b_{c}}}{1+\frac{b_{p}}{b_{c}}}}
$$

where the bond length coefficient $\beta_{L}$ can be calculated according to Equation (8):

$$
\beta_{L}= \begin{cases}1 & l \geq l_{e} \\ \sin \left(\frac{\pi l}{2 l_{e}}\right) & l<l_{e}\end{cases}
$$

and where the effective bond length $l_{e}$ can be calculated according to Equation (9):

$$
l_{e}=\sqrt{\frac{E_{C F R P} t_{C F R P}}{\sqrt{f_{c}^{\prime}}}}
$$

In addition, Yang Yong Xin et al. [11]proposed an alternative equation to Equation (6):

$$
\sigma_{d b i c}=0.9 \cdot E_{C F R P} \frac{\beta t_{a} f_{t}}{G_{a}} \frac{e^{\beta l_{m} / 2}+e^{-\beta l_{m} / 2}}{e^{\beta l_{m} / 2}-e^{-\beta l_{m} / 2}}
$$

where $I_{m}$ is calculated in $\mathrm{cm}, \beta$ can be calculated according to Equation (11):

$$
\beta=\sqrt{\frac{G_{a}}{t_{a} t_{C F R P}}\left(\frac{1}{E_{C F R P}}-\frac{A_{C F R P}}{E_{c} A_{t e}}\right)}
$$

and where can be calculated according to Equation (12), where $=1.96 \mathrm{MPa}$ :

$$
l_{m}=\frac{1.5 A_{t e} f_{t}}{0.313 \sqrt{f_{c}^{\prime}} \cdot \sum o_{b a r s}+u_{C F R P} b_{P}}
$$

\subsubsection{Bearing-Debonding Capacity}

Using Equations (6) and (10), the ultimate stress of debonding CFRP $\sigma_{d b i c}$ can be determined along with the equivalent compressive strength of CFRP $f_{\text {CFRPS }}$, which is the smaller value between the ultimate compressive strength $f_{C F R P}$ and debonding destruction ultimate stress $\sigma_{d b i c}$, as shown in Equation (13):

$$
f_{C F R P, r}=\min \left(f_{C F R P}, \sigma_{d b i c}\right)
$$

where the debonding stress of CFRP can be determined according to Equation (14):

$$
\varepsilon_{C F R P}=\frac{f_{C F R P, r}}{E_{C F R P}}
$$

Given the debonding strain of CFRP in the cracks, $\varepsilon_{C F R P}$, the debonding bending moment can be determined by a planar cross-section assumption and the equivalent stress figure, as shown in Fig. (18). 
Ignoring the thickness of the CFRP layer and the gel, the debonding bending moment $M_{u}$ can be calculated according to Equations (15) and (16):

$$
\begin{gathered}
M_{u}=f_{c d} b_{c} x\left(h_{0}-\frac{x}{2}\right)+f_{C F R P, r} A_{C F R P} a_{s} \\
f_{c d} b_{c} x=f_{C F R P, r} A_{C F R P}+\sigma_{s} A_{s}
\end{gathered}
$$

\subsubsection{Analysis of the Debonding Experiment}

All five specimens appear to show evidence of plastic destruction. After breakage, loading on JM-0 increases, the cracks develop rapidly, and the neutral axis rises continuously. Beyond a certain point, the compressive bearing strength of concrete in the pressing regions is exhausted, the concrete is pressed into fragments, and the slab is destroyed. However, the tensile stress of the vertical steel keeps the yield strength high.

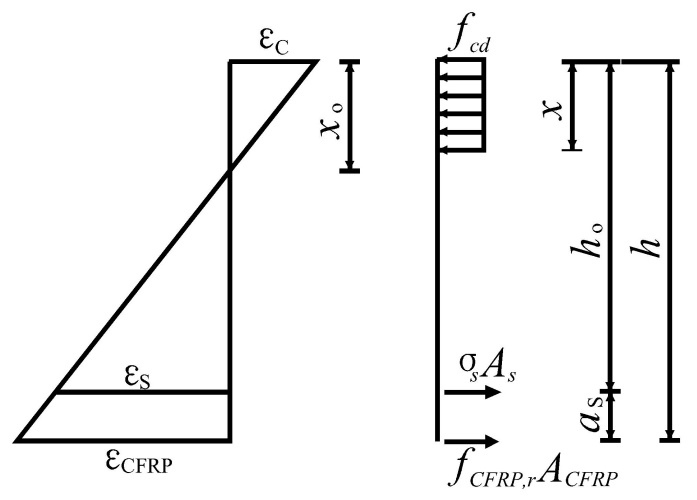

Fig. (18). Planar cross-section assumption.

After breakage, the cracks on JM-1 develop slowly, and the number and density of cracks were found to be greater than those of TM-0, with the neutral axis rising slowly. It was also found that debonding appeared in the end anchored by two CFRP-stripes separated by $50 \mathrm{~mm}$. At that time, the steel was surrounded, the CFRP had debonded, the compressive bearing strength of concrete in the pressing regions was exhausted, and the slab was destroyed. Breakage of JM-2 was similar to that of JM-1, with debonding occurring at the end anchored by the bolt. As TM-1 was exposed to wheel grinding at high temperatures, its crack loading dropped slightly, and its ultimate loading remained unchanged. The process and features of breakage were found to be similar to those of JM-1. Debonding appeared at the end anchored by two CFRP-stripes separated by $50 \mathrm{~mm}$, and the degree of debonding was relatively large. As for TM-1, TM-2 was also exposed to wheel grinding at high temperatures; hence, its crack loading and ultimate loading also dropped. It could therefore be assumed that the process and features of breakage were similar to those of JM-2, with debonding appearing at the end anchored by the bolt. Upon debonding of the CFRP, it is pulled to the point of breaking and the concrete slab is destroyed. Regional breakages can be seen in Figs. (19-22).

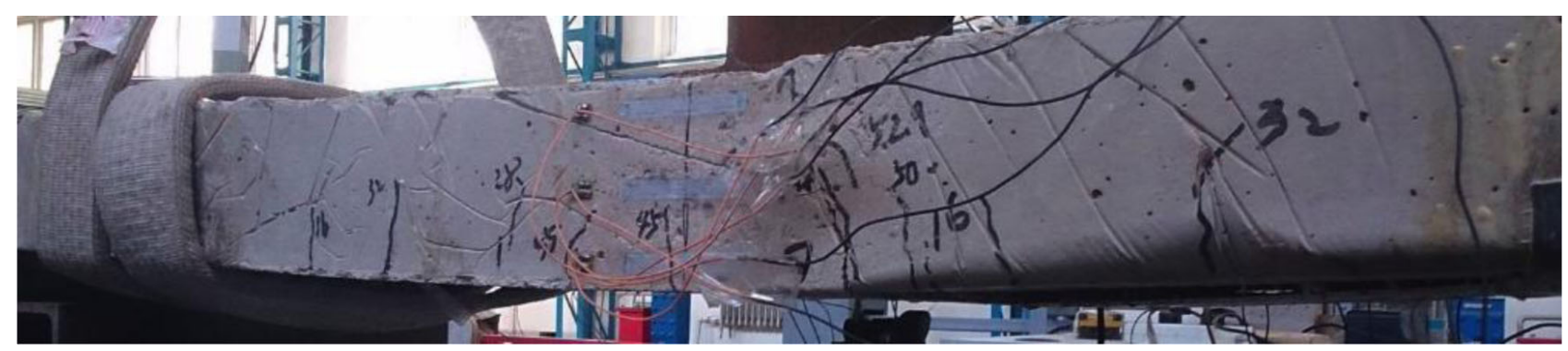

Fig. (19). JM-1 CFRP debonding breakage. 


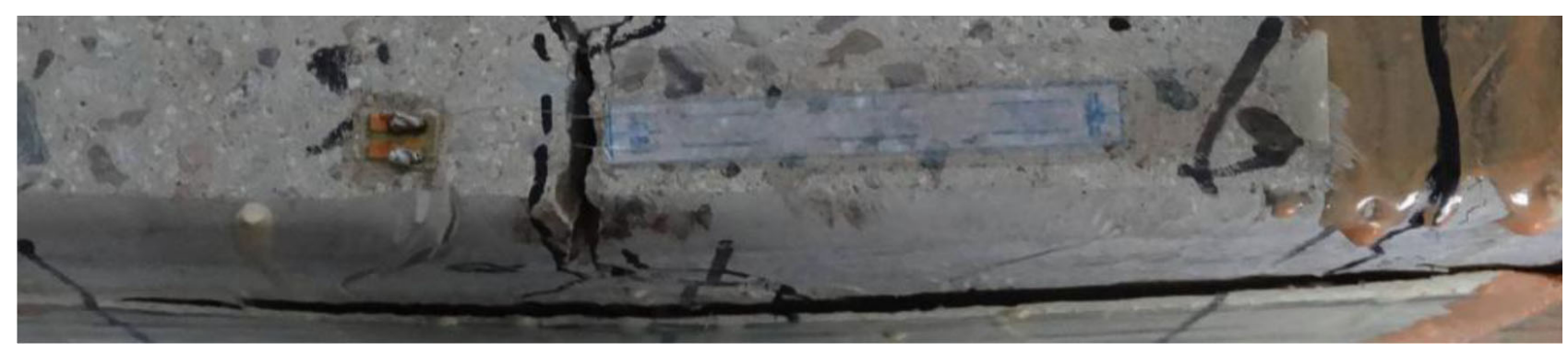

Fig. (20). JM-2 CFRP debonding breakage.

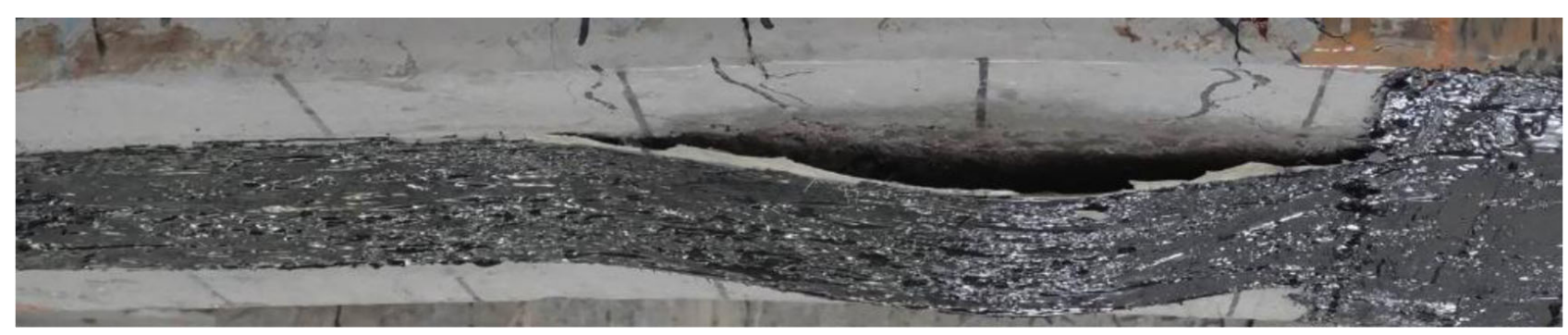

Fig. (21). TM-1 CFRP debonding breakage.

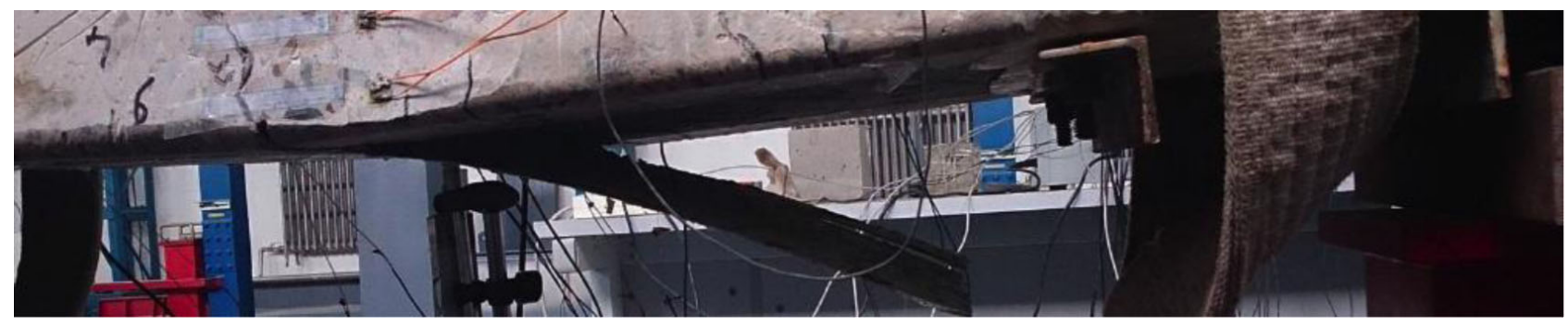

Fig. (22). TM-2 CFRP debonding breakage.

Table 2 shows experimental and theoretical values of the bearing-debonding capacities. It was found that the theoretical values calculated using methods 1 and 2 (from the equations previously described) are comparable. The two theoretical values of the bearing-debonding capacities were then compared with the experimental values. We found that the theoretical values were higher than that of the unreinforced slab by approximately $12 \%$, whereas the experimental values obtained from different reinforced methods were higher than the theoretical values by $20-30 \%$, and higher than that of the unreinforced slab by $35-45 \%$. It therefore appears that a certain amount of safety storage exists. Finally, following wheel grinding at high temperatures, the experimental value of the bearing-debonding capacity was found to vary only slightly; hence, the influence of wheel grinding at high temperatures could be ignored. We can therefore conclude that the CFRP anchor and the bolt anchor have an equivalent effect.

Table 2. Experimental and theoretical values of bearing-debonding capacities.

\begin{tabular}{|c|c|c|c|c|c|c|}
\hline \multirow{3}{*}{ Type } & \multirow{3}{*}{ Number } & \multicolumn{5}{|c|}{ Bearing-debonding capacity* } \\
\hline & & \multirow{2}{*}{ Experimental value $(\mathrm{KN} \cdot \mathrm{m})$} & \multicolumn{3}{|c|}{ Theoretical value/KN·m) } & \multirow{2}{*}{$\begin{array}{c}\text { Ratio between experimental and } \\
\text { theoretical value }(\%)\end{array}$} \\
\hline & & & Method $1[10]$ & Method 2 [11] & Average & \\
\hline \multirow[t]{2}{*}{ Wheel grinding } & JM-1 & 19.3 & 15.4 & 14.4 & 14.9 & 129 \\
\hline & JM-2 & 19.0 & 15.4 & 14.4 & 14.9 & 127 \\
\hline \multirow{2}{*}{$\begin{array}{l}\text { Wheel grinding at high } \\
\text { temperature }\end{array}$} & TM-1 & 19.2 & 15.4 & 14.4 & 14.9 & 128 \\
\hline & TM-2 & 18.3 & 15.4 & 14.4 & 14.9 & 123 \\
\hline
\end{tabular}

* The ultimate bearing-debonding capacity of JM-0 is $13.3 \mathrm{KN} . \mathrm{m}$

\section{CONCLUSION}

We performed indoor shear, tensile, and debonding tests for improving the cohesion of carbon fibre reinforced 
polymer (CFRP) in bridge deck slabs. We also analysed the change rule of cohesion in three different environments, and determined the optimum construction technique for improving the cohesion of CFRP. From the results obtained in our study, the following conclusions could be drawn:

1. To obtain acceptable shear strength, manufactured sand should be spread on the surface of the impregnating resin adhesive.

2. Soaking, freeze thawing, and wheel grinding processes were found to have an influence on the tensile strength of the interface, which was linearly related to the shear strength of the interface. The tensile strength of the interface between CFRP and the bridge pavement can therefore be optimised to meet the necessary requirements for an application.

3. Following wheel grinding on an asphalt surface at high temperatures, the test value for the bearing-debonding capacity on a test slab was unchanged, and the effectiveness of CFRP was still apparent. The influence of hightemperature wheel grinding can therefore be ignored. The CFRP anchor and the bolt anchor had an equivalent effect.

4. Through the reinforcement of bridge deck slabs, using sand spreading, modified asphalt, and CFRP anchoring, according to the experimental parameters reported herein, problems such as slippage, disengaging, and debonding are less likely to occur.

We therefore expect that the results from our study can serve as a reference for the design of reinforced bridge deck slabs.

\section{NOTATIONS USED IN FIGURES AND EQUATIONS}

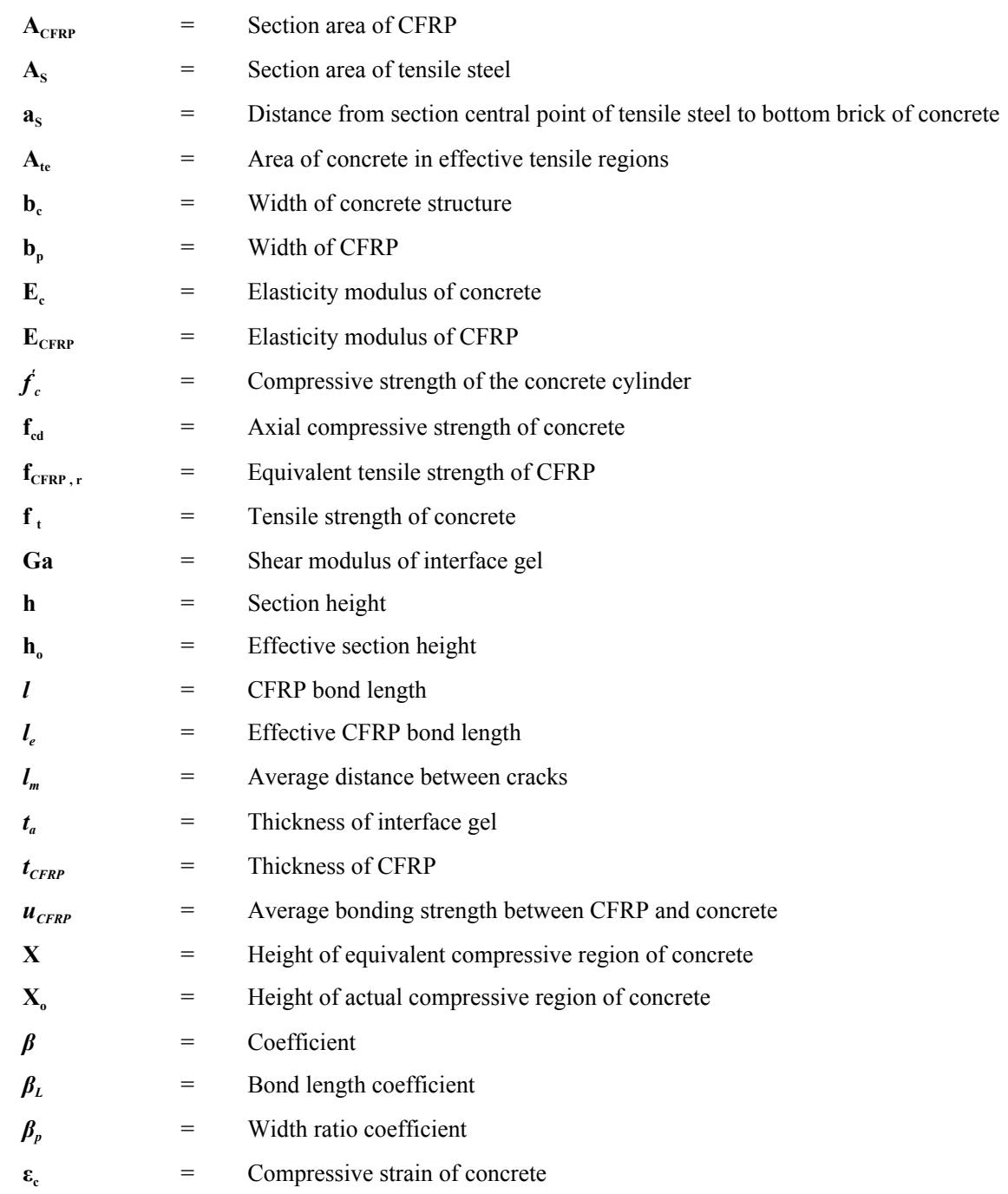




$\begin{array}{lll}\boldsymbol{\varepsilon}_{\mathrm{CFRP}} & = & \text { Tensile strain of CFRP } \\ \boldsymbol{\varepsilon}_{\mathrm{s}} & = & \text { Tensile strain of tensile steel } \\ \boldsymbol{\sigma}_{\mathrm{s}} & = & \text { Stress of tensile steel } \\ \sum o_{\text {bars }} & = & \text { Total perimeter of tensile steel }\end{array}$

\section{CONFLICT OF INTEREST}

The authors confirm that this article content has no conflict of interest.

\section{ACKNOWLEDGEMENTS}

Declared none.

\section{REFERENCES}

[1] X. Li, and X. Yuan, "Study on epoxy mortar and concrete interface stress of box girder bridge top slab subjected to high temperature", Journal of Construction Technology, vol. 42, pp. 17-19, 2013.

[2] R. Al-Rousan, M. Issa, and H. Shabila, "Performance of reinforced concrete slabs strengthened with different types and configurations of CFRP", Journal of Composites Part B: Engineering, vol. 43, no. 2, pp. 510-521, 2011.

[3] H.M. Elsanadedy, S.H. Alsayed, Y.A. AL-Salloumand, and T.H. Almusallam, "Experimental and FE study on RC one-way slabs upgraded with FRP composites", KSCE Journal of Civil Engineering, vol. 19, no. 4, pp. 1024-1040, 2014 [http://dx.doi.org/10.1007/s12205-013-0689-y]

[4] Y. Zhu, and Y.X. Zhang, "Nonlinear finite element analyses of FRP-reinforced concrete slabs using a new layered composite plate element", Journal of Computational Mechanics, vol. 46, pp. 417-430, 2010. [http://dx.doi.org/10.1007/s00466-010-0485-1]

[5] U.A. Ebead, and H. Marzouk, "Tension-stiffening model for FRP-strenghened RC concrete two-way slabs", Journal of Materials and Structures, vol. 38, pp. 193-200, 2005.

[6] S.T. Smith, S. Hu, S.J. Kim, and R. Seracino, "FRP-strengthened RC slabs anchored with FRP anchors", Engineering Structures, vol. 3, no. 4, pp. 1075-1087, 2011.

[http://dx.doi.org/10.1016/j.engstruct.2010.11.018]

[7] A. Ahmed, and V.K. Kodur, "Effect of bond degradation on fire resistance of FRP-strengthened reinforced concrete beam", Journal of Composites Part B: Engineering, vol. 42, no. 2, pp. 226-237, 2011.

[http://dx.doi.org/10.1016/j.compositesb.2010.11.004]

[8] M.S. Issa, "Comparative study for punching of FRP-reinforced concrete slabs", Arabian Journal of Sciences and Engineering, vol. 38, no. 10, pp. 2601-2617, 2013 [http://dx.doi.org/10.1007/s13369-012-0496-7]

[9] S.C. Kwon, P.K. Dutta, and Y.H. Kim, "Comparison of the fatigue behaviors of FRP bridge decks and reinforced concrete conventional decks under extreme environmental conditions", KSME International Journal, vol. 17, no. 1, pp. 1-10, 2003.

[10] J.F. Chen, and J.G. Teng, "Anchorage strength models for FRP and steel plates bonded to concrete", Journal of Structural Engineering, vol. 127, no. 7, pp. 784-791, 2001.

[http://dx.doi.org/10.1061/(ASCE)0733-9445(2001)127:7(784)]

[11] Y. Yang, Q. Yue, L. Ye, and Y. Hu, "Debonding failure of reinforced concrete beams strengthened with carbon fiber sheets", Journal of Engineering Mechanics, vol. 21, no. 5, pp. 130-157, 2004.

Received: July 25, 2015 Revised: September 28, 2015 Accepted: September 29, 2015

(C) Shuai et al; Licensee Bentham Open.

This is an open access article licensed under the terms of the Creative Commons Attribution-Non-Commercial 4.0 International Public License (CC BY-NC 4.0) (https://creativecommons.org/licenses/by-nc/4.0/legalcode), which permits unrestricted, non-commercial use, distribution and reproduction in any medium, provided the work is properly cited. 